1. The trustees and the electors have refrained from appointing a successor to the late Dr. Jackson simply in view of the fact that very shortly after his death, negotiations for the proposed transfer were set on foot, pending which it would have been undesirable to make any fresh appointment.

2. In fact, the Library has been during the last few years most admirably carried on by the sublibrarian, Mr. James Ford, whose services the University has recently recognised by conferring on him the degree of M.A., honoris causa.

3. The second paragraph is a travesty of what is proposed. Had the writer, or the person who furnished the materials, candidly examined the print of the scheme of transfer which appeared in two numbers of the Oxford University Gazette (Feb. 2 and 9, 1927), he must have observed that all existing facilities and privileges of readers and students in the Radcliffe Science Library are preserved with meticulous care, including in particular ' the open shelf' and the right of taking books out into the various scientific depart. ments of the University Museum.

4. In regard to the suggestions which both paragraphs make, that during these three years "the Library has lost many books by theft" (an inevitable source of loss which is in some degree common to all public libraries), the plain fact is that the annual proportion of such losses has fallen very much during the period in question: such books as have been so lost are current text-books of small pecuniary value, and their actual number is exceedingly small.

COTTESLOE.

(Chairman of the Radeliffe Trustees.)

1. Lord CotTessoe does not explain why the Radcliffe Trustees, in negotiating the transfer of scientific books to the University, would not have been greatly assisted if they had had the benefit of the inside scientific knowledge of their own Librarian. Their readers have been deprived of his expert aid for three years, and that is a long time in the history of a science library, or in the life of an undergraduate.

2. The merits of Mr. Ford and his invariable courtesy on trying occasions are recognised by all who use the Library ; but he would be the last person to lay claim to that special knowledge of scientific literature for which generations of Radcliffe Librarians have been famous and helpful.

3. The past success of the Science Library has undoubtedly been partly due to the above-mentioned facilities, wisely given by former Librarians. It is exceedingly doubtful whether the proposed association with the Bodleian Library will lead to the improvement of those facilities. The experience of many a reader is that the difficulties of obtaining books from the Bodleian for use in the Radcliffe Library are so great as to be deterrent.

4. Complaints of undergraduates who, on the eve of examination, are deprived of text-books, even. though " of small pecuniary value," evidently ring louder in the ears of their tutors than in those of the Radeliffe Trustees.

$$
\text { The Writer of the Notes. }
$$

\section{A Novel Type of Optically Active Complex Metallic Salt.}

WERNER's conception of co-ordinated groups and of auxiliary valency has been extraordinarily useful in classifying and in elucidating the configurations of complex metallic compounds. Although many salts of this class, such as tris-ethylenediamine cobaltic chloride $\left[\mathrm{Co}\left(\mathrm{NH}_{2}, \mathrm{CH}_{2} \cdot \mathrm{CH}_{2} \cdot \mathrm{NH}_{2}\right)_{3}\right] \mathrm{Cl}_{3}$, have been resolved into optically active components, no proof has hitherto been given that an auxiliary valency linking can render a carbon atom asymmetric. This interesting proposition has been now established by the further study of the recently described salt, tetrachloro- (triaminopropane monohydrochloride)platinum, $\mathrm{PtCl}_{4}, \mathrm{NH}_{2} \cdot \mathrm{CH}_{2} \cdot \mathrm{CH}\left(\mathrm{NH}_{2}\right) \cdot \mathrm{CH}_{2} \cdot \mathrm{NH}_{2}, \mathrm{HCl}$, obtained by the action of the $\alpha \beta \gamma$-triaminopropane hydrochloride on chloroplatinic acid (Mann, Jour. Chem. Soc., r29, 2681; 1926).

In the new salt the components, $\mathrm{PtCl}_{4}$ and two of the $\mathrm{NH}_{2}$-groups with some of the associated carbon and hydrogen atoms, must lie inside the co-ordinated group, whilst the third $\mathrm{NH}_{2}$-group must protrude therefrom. It has now been found that the salt can be resolved into optically active components by the aid of silver $d$ - and $l$-camphorsulphonate. The two salts, $l$-base $d$-acid, and $d$-base $l$-acid, have thus been obtained in an optically pure state; the hydrochlorides regenerated from these salts give molecular rotations of $-502^{\circ}$ and $+501^{\circ}$ respectively for the mercury green line in aqueous solution at $15^{\circ}$.

It is clear, therefore, that the constitution of the hydrochlorides must be represented by the following formula :

$$
\left[\begin{array}{ccc}
\mathrm{Cl} & \mathrm{PH}_{\mathrm{Cl}}^{\mathrm{Cl}} & -\mathrm{NH}_{2}-\mathrm{CH}^{\mathrm{C} H} \\
\mathrm{Cl} & \mathrm{NH}_{2}-\mathrm{CH}_{2}
\end{array}\right]
$$

In the above formula the enantiomorphism of configuration is associated with asymmetry of the middle or $\beta$-carbon atom of the triaminopropane molecule ; this asymmetry arises from the attachment of the $\alpha$ - and $\beta$-amino-groups to the platinum atom by auxiliary valencies. This is the first case to be recorded in which asymmetry of a carbon atom. results from the operation of auxiliary valencies.

The new type of molecular enantiomorphism now disclosed will no doubt appear among numerous complex metallic compounds and, indeed, a complex copper salt, analogous in constitution to the above platinum salt, has been already prepared (loc. cit.). We are now engaged on the further investigation of these and other related compounds.

$$
\begin{aligned}
& \text { F. G. Mann. } \\
& \text { W. J. Pope. }
\end{aligned}
$$

The Chemical Laboratory,

University of Cambridge, Feb. 7.

\section{Migration and Reproductive Rhythm in Birds.}

IN a previous letter (Nature, April 4, 1925) a brief account was given of an attempt to break the annual reproductive rhythm in the Junco (Junco hyamelis) and to induce premature recrudescence of the gonads in the middle of the winter. It was suggested that migration might be dependent on the production of a hormone by the organs w'ililst in a certain stage of regeneration. Thanks to a research grant from the Royal Society, I have this winter been able to repeat and extend my earlier investigations. Nearly two hundred Juncos were trapped on their southward migration in the autumn and divided, as before, between two aviaries. The experimental one has been artificially lit since Oct. 1, beginning on the first day with 5 minutes after darkness, 10 on the second, 15 on the third, and so on. The controls got no artificial light. Their day was therefore decreasing, while that of the experimentals was increasing artificially at about the same rate as it would have been normally in the spring. Neither aviary is heated.

An experimental Junco was killed along with a control on Dec. 30, 1926, and dissected. In this experimental bird the testes were large and conspicuous

No. 2992, VoL. 119] 